\title{
Network Analysis for A Community Based School- and Family-Based Obesity Prevention Program
}

Katharina Brauer ( $\nabla$ katharina.brauer@uni-leipzig.de)

Leipzig University: Universitat Leipzig https://orcid.org/0000-0002-2547-7361

\section{Hagen Wulff}

University of Potsdam: Universitat Potsdam

\section{Sabine Pawellek}

Leipzig University: Universitat Leipzig

\section{Alexandra Ziegeldorf}

Leipzig University: Universitat Leipzig https://orcid.org/0000-0002-8405-8829

\section{Research Article}

Keywords: network analysis, obesity prevention, community health promotion, collaboration

Posted Date: February 25th, 2022

DOI: https://doi.org/10.21203/rs.3.rs-1238161/v1

License: (9) This work is licensed under a Creative Commons Attribution 4.0 International License. Read Full License 


\section{Abstract}

\section{Background}

Rising childhood obesity with its derimental health consequences is a multifactorial phenomenon and poses a challenge to the health care system. To tackle its complexity, community-based interventions with focus on the involvement of different settings and stakeholders are emerging as promising so far. The project 'Familie ${ }^{+}$- Gesundes Zusammenleben in Familie und Schule' ('Family ${ }^{+}$- Living healthily together in family and school') is a community-based intervention aiming to prevent obesity among primar school children in three German municipalities and is based on a multi-setting and participatory approach. This study applies network analysis to examine network relations between stakeholders potentially relevant to the project in two rural and one urban model region in Germany.

\section{Methods}

Telephone surveys were conducted to assess several key variables including frequency of contact and intensity of collaboration. Community health promotion was established differently in all three model regions at the time of the survey. Process characteristics such as density, centrality, and connectedness were analyzed using UCINET 6.0 software and graphical representations of the networks were created using NetDraw.

\section{Results}

The networks were mainly characterized by their different sizes as well as different distribution of network partners in terms of their subject matter and structure. Network partners interact with each other mostly on a quarterly basis and in the context of informal collaboration.

\section{Conclusions}

Based on the results of the network analysis, it appears to be useful to initialize a community health facilitator provided with necessary resources and training at the health policy level in community health promotion projects, irrespective of the rural or urban structure of the region. The participatory involvement of relevant actors initiated by the facilitator can have a positive influence on the effective dissemination of information and networking with other stakeholders.

\section{Background}

'Complex problems' describe a mechanism in which multiple factors and actors are involved and interconnected either through direct or indirect links. This multiplicity of connections makes it impossible to predict the effect of a single intervention (1). This is why solving complex problems requires multiple intervention approaches that go beyond the focus of personal responsibility (2). Applied to the context of public health, one of the major problems of the 21 st century affecting children worldwide can be identified: overweight and obesity. In general, overweight and especially obesity in children and 
adolescents are associated with adverse health outcomes in the long term (3) with higher risk of developing non-communicable diseases or co-morbidities and premature death in adulthood (4). Rising childhood obesity with its derimental health consequences is a multifactorial phenomenon and poses a challenge to the health care system (5) as its complexity leads to a continuous expansion of this problem $(6,7)$.

To date, there have been diverse approaches to obesity prevention that focus on single factors, such as the canteen menu in the school setting or parenting skills in the family unit (8). However, this approach has largely proven ineffective (9), resulting in a shift from individually-focused interventions to systemwide, community-based interventions which are emerging as promising so far $(10,11)$. Community-based interventions should be designed with a focus on the target group and appropriate community penetration in order to achieve comprehensive behavior change which begins at the individual level and depends on reinforcement and acceptance at the community level (12). Speaking of different levels and health, an approach from social ecology immediately comes to mind, namely the rainbow model of Dahlgren and Whitehead (13), which identifies different determinants of individual health that operate in the context of different settings and levels. Networks run throughout this model, but the question arises as to where they are found, what they look like and who exactly is involved. There is often an ideal-typical categorization of network levels into primary (micro level, i.e. individual), secondary (meso level, i.e. local associations, public institutions and organizations) and tertiary networks (macro level, i.e. institutions at superordinate or local government level) which determine health (14) and originate from the ecosystemic theory of Bronfenbrenner (15). In order to promote and strengthen health in the sense of the socioecological approach, network characteristics and the interaction of the three network levels with its actors must be identified (16). This can be accomplished by including different settings (multi-setting approach) as well as different key actors (participatory approach), which is very important as they can play a positive and proactive role in changing factors that put the target population at risk of unhealthy behaviors (12). To engage stakeholders, these key actors must first be identified by means of a stakeholder analysis. Subsequently, stakeholder network's structure can be explored using network analysis. Network analysis serves as a suitable tool to gain insights into the complex structural and processual characteristics of stakeholder networks within community-based interventions (16) and can assist in developing an understanding of the roles which stakeholders play in the outcomes of a network. Suitable measures for assessing network characteristics are density and centrality, while the interaction of actors is surveyed in terms of frequency and intensity of contact (17).

To date, there are several studies that have analyzed networks in the context of community obesity prevention interventions $(2,18-22)$. However, the networks often consisted only of stakeholders from higher network levels, for example steering committees, local governments or institutions delivering obesity prevention intitiatives. Since it is assumed that successful health promotion occurs through the interaction of the aforementioned health-related network levels, it is important to capture the type and extent of stakeholder interaction. The objective of this research was to identify the network of relevant stakeholders from all network levels for the project 'Familie+ - Gesundes Zusammenleben in Familie und Schule' ('Family+ - Living healthily together in family and school'). 'Familie+' is based on a community- 
based, participatory approach aimed at preventing obesity in primary school children in German municipalities. The multi-setting approach involves the joint implementation of evidence-based measures to change weight-related behavior (physical activity, sedentary behavior, nutrition, sleep) in the settings important to children, including family and school. The respective measures will be selected, adapted and implemented in the two settings family and school in a participatory approach together with the relevant stakeholders. This paper applies network analysis to analyze network relationships among stakeholders potentially relevant to the project as well as participating elementary schools in three municipalities in Germany. In particular, structural and processual characteristics were used to identify community network structures and to map existing relationships and collaborations. The three model regions were compared against the background of different community structures (urban versus rural) and varying levels of prior experience in the field of community health promotion. The aim of the study was to use network analysis as an applicable tool for evaluating stakeholder networks at the baseline of a community-based prevention intervention. With the results obtained, the network structures and possible differences of the participating model regions can be mapped which may be profitable in terms of derivations for the further course of the intervention.

\section{Methods}

\section{Subjects and Setting}

This study included a total of three model regions in Germany as part of the 'Familie ${ }^{+\prime}$ project: two of them being rural with their populations of about 143,000 (network\#1) and 211,000 (network\#2), respectively, and the third region being urban with its population of 590,000 (network\#3). Community health promotion is established differently in all three model regions. It is already most pronounced in the urban region (network\#3), whereas it is moderately established within one rural region (network\#1) and is still in its early stages in the other rural region (network\#2).

\section{Network analysis: Preparation}

In order to identify potentially relevant stakeholders for the research project 'Familie ${ }^{+\prime}$ in the selected municipalities, a stakeholder analysis was carried out in the period May 2020 - July 2020. Following the preliminary theoretical work and literature search of similar research projects in scientific data bases, expert interviews following Mieg and Näf (23) were conducted. Meta-level experts were defined as individuals who have at least ten years of professional experience in the setting of community health promotion and/or have already initiated and implemented at least two community health promotion projects. Experts in the community setting were defined as persons who have several years (at least five) of professional experience in the community health promotion setting and/or have already initiated and/or implemented and/or accompanied one or more project(s) on community health promotion. Based on this, individual expert interviews were conducted to identify all potential stakeholders in the three selected municipalities. All interviews were guided and conducted by telephone (due to the Corona pandemic) and fully transcribed and analyzed according to an extended simple transcription system by 
Dresing and Pehl (24). Thereafter, all interviews were analyzed with the qualitative content analysis according to Mayring (25) and the results on all potential stakeholders were presented on the meta-level as well as separately for the three model regions in individual mind maps.

After all potentially relevant stakeholders were identified, the network analysis was conducted separately for the three selected model regions in the time period November 2020 - January 2021. Subsequently, data entry and evaluation took place from February 2021 - June 2021.

\section{Network analysis: Execution}

In order to establish initial contact with all stakeholders identified as potentially relevant in the stakeholder analysis, a network analysis was conducted. To capture the type and extent of stakeholder interactions from all network levels, the strategy of examining networks as a whole was chosen, analyzing what types of relationships each actor in a given study set of actors (here: model region) maintains or does not maintain with every other actor in that set (26). In preparation for the potentially relevant stakeholders, e-mails were sent with information about the project, the privacy policy and the network analysis procedure. Letters were sent to all participants to obtain written informed consent prior to conducting the telephone surveys. Three to five days later, they received a call from an employee of the University of Leipzig to arrange an appointment to conduct the telephone survey. For all telephone surveys, institution-specific questionnaires (see Additional file 1) were developed to keep track as a surveyor as well as to ensure that institutions could not rate the relationship to themselves. For example, if 30 institutions were identified within a community, all 30 institutions were asked to answer the questions posed with respect to the other 29 institutions. During the interview, the questions were systematically worked through and noted on the questionnaire by the trained interview guide. Afterwards, the data were anonymized by coding and stored in accordance with data protection regulations. Following Schoen, Moreland-Russell (27) and Schnegg and Lang (26), the survey included a series of questions to assess several key variables including frequency of contact, level of collaboration (28) as well as communication channels and objects of communication in the context of municipal health promotion with the respective network partners. Participants were presented with a raster of names of other institutions in their network and reported on key variables for each institution. They were first asked whether they knew the institution and generally had contact with it. These questions serve as a basis for the later analysis of network density and centrality measures by which statements about the individual integration of an actor into the overall structure can be derived (26). If the answer was 'yes,' they were asked on a six-point scale how often they had direct contact with each of the other people in their network about community health promotion in the past year: no contact, yearly, quarterly, monthly, weekly, and daily. Collaboration was assessed with a scale adapted from established network analytic methods (29). Participants were asked to select the response that best describes the relationship in the last year with each of institutions on the roster. Response options ranged from not linked (do not work together), communication (share information only), cooperation (work together informally to achieve common goals), collaboration (work together as a formal team with specific responsibilities), and fully linked (work together as a formal team; mutually plan and share staff or resources to accomplish goals). 


\section{Network analysis: Evaluation}

The networks were presented separately by model region. To examine structural patterns, network analysis represents key actors (26) as the smallest unit (node) in the network (30) while social relationships are visualized as ties between nodes, constituting the main focus of a network (31). The relationships of potentially relevant stakeholders within a network were mapped in the form of a matrix that gives information about the existence and relationship between to actors. If the upper and lower halves of the diagonal are identical, the matrix is called symmetric and the relation of one actor is reciprocated by its counterpart. Furthermore, a distinction is made between weighted and unweighted matrices: in the case of an unweighted matrix, statements are only made about the (non-)presence of a relationship, but none about the intensity of the relationships (26). Furthermore, network analysis can be used to represent process characteristics as well as to predict inter-organizational communication and collaboration and to measure partnership characteristics in community health promotion $(17,32)$. Process characteristic as density (number of actually existing connections expressed as a proportion of all possible relationships), centrality (degree centrality: number of incoming and outgoing relationships of an actor; betweenness centrality: indicator for the influence of an actor in a network and gives information about the extent of its control potential), homophily (similarity of actors with respect to certain characteristics or attributes; values between -0.5 and $-1=$ homophilic, values between 0.5 and $1=$ heterophilic, values between -0.5 and $0.5=$ neutral) and connectedness (frequency and intensity of contact) were examined $(26,33)$.

All analyses were performed with UCINET 6.0 software and NetDraw network visualization tool was used to generate graphical representations of each network (34).

\section{Results}

A total of 69 potentially relevant stakeholders from the three model regions were contacted to participate in the network analysis. Overall, the response rate was $67 \%$, with individual response rates of $65 \%$ for network\#1,70\% for network\#2 and $67 \%$ for network\#3. The characteristics of each model region in terms of number of potential stakeholders, associated structural level, and subject area are shown in Table 1. This table provides a very comprehensive overview and lists all stakeholders as sequential numbers for each network, which will be relevant for both Figures 2 and 4 .

Table 1 Subject area and structural level of the networks 


\begin{tabular}{|c|c|c|c|c|}
\hline \multirow{2}{*}{ Subject area } & \multirow{2}{*}{ Colour } & \multicolumn{3}{|c|}{ Stakeholders from } \\
\hline & & network\#1 & network\#2 & network\#3 \\
\hline Health (superordinate level) & & $2,4,5,6,8,13$ & 3 & 6,7 \\
\hline Nutrition & & 3,9 & 1 & 2,3 \\
\hline Sports/Exercise & & $10,15,18$ & 2 & $1,4,5$ \\
\hline Leisure & & 12 & $6,11,14$ & 8,12 \\
\hline Family & & $7,14,20$ & 5 & 9,10 \\
\hline Primary schools & & $16,17,19$ & $8,9,10,12,13$ & 11 \\
\hline $\begin{array}{l}\text { Social and educational } \\
\text { institutions (focus on health) }\end{array}$ & & 1,11 & 4,7 & - \\
\hline \multirow{2}{*}{ Structural level } & \multirow{2}{*}{ Symbol } & \multicolumn{3}{|c|}{ Stakeholders from } \\
\hline & & network\#1 & network\#2 & network\#3 \\
\hline $\begin{array}{l}\text { Office level (higher, } \\
\text { communally organized level) }\end{array}$ & & $4,6,13$ & 3,5 & $\begin{array}{l}4,5,6,7 \\
9\end{array}$ \\
\hline $\begin{array}{l}\text { Network level (networking } \\
\text { agencies) }\end{array}$ & & $\begin{array}{l}2,3,5,7,8,9 \\
10\end{array}$ & 1,2 & 2,3 \\
\hline Association level (local level) & & $\begin{array}{l}1,11,12,14 \\
15,18,20\end{array}$ & $4,6,7,11,14$ & $\begin{array}{l}1,8,10 \\
12\end{array}$ \\
\hline Primary schools & 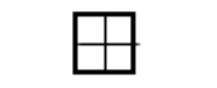 & $16,17,19$ & $8,9,10,12,13$ & 11 \\
\hline
\end{tabular}

The network analysis was conducted separately by model region and the results are presented in more detail in the next sections.

\section{Network characteristics}

Table 2 shows the network structure summaries. All measures are for undirected ties which means that statements are only made about the (non-)existence of a relationship, but not about the intensity of the relationships. On average, network\#1 was bigger and had a higher average degree than network\#2 and network\#3. The relationships of two actors are reported from both positions per network, so in network\#1 with 20 actors there are a total of 400 possible contacts. 
Table 2

Summary of network characteristics

\begin{tabular}{|llll|}
\hline & network\#1 & network\#2 & network\#3 \\
\hline & Mean & Mean & Mean \\
\hline Network size & 20 & 14 & 12 \\
\hline Number of ties & 184 & 94 & 56 \\
\hline Contact opportunities & 400 & 196 & 144 \\
\hline Average degree & 9.20 & 6.74 & 4.67 \\
\hline Network density & 0.48 & 0.52 & 0.42 \\
\hline Average distance & 1.52 & 1.54 & 1.64 \\
\hline Degree centrality & 0.57 & 0.39 & 0.58 \\
\hline Homophily (subject area) & 0.61 & 0.68 & 0.57 \\
\hline Homophily (structural level) & 0.41 & 0.32 & 0.25 \\
\hline $\begin{array}{l}\text { Structural signatures defined according to Schnegg and Lang (26): } \\
\text { • Network size: number of actors (nodes) in the network }\end{array}$ \\
• Number of ties: number of existing connections (edges) between actors \\
• Contact opportunities: expressed from both positions per network \\
• Average degree: average number of links each node in the network has \\
• Average distance: average path length among connected pairs
\end{tabular}

network\#1 has the highest average degree with an average number of nine links. network\#2 and network\#3 follow, matching the decreasing network size, with almost seven and almost five average links per node, respectively.

The network density of network\#2 is 0.52 , meaning that this network contains more than half $(52 \%)$ of the possible edges expected in a completely interconnected network. Compared to the other networks with $48 \%$ for network\# 1 and $42 \%$ for network\#3, network\#2 has the highest density with its network size of 14 institutions.

The average path length within network\#1 and network\#2 networks is very similar, the length of network\#3 is slightly longer at 1.64, meaning institutions are able to reach each other by following 1.64 causal paths, on average.

Degree distributions of all networks are shown in Figure 1. 
Since there are three non-symmetric networks, the in-degree and out-degree values of the individual institutions are not uniform. The distribution of node in-degree ranges from 4 to 16 for network\#1, from 1 to 12 for network\#2 and from 2 to 9 for network\#3. For network\#1 (d) and network\#2 (e) the institution with the highest indegree value is a social and educational institution from the local level with focus on health, whereas for network\#3 (f) the most popular institution with the highest value is a higher, communaly organized institution with its focus on health. This institution also has the highest outdegree value (c), whereas at network\#1 (a) one institution at the network level in the field of nutrition and at network\#2 (b) one of the elementary schools and also a social and educational institution with focus on health at the local level have the highest level of expansivity within the network.

Degree centrality is very similar for network\# 1 and network\#3 at 0.57 and 0.58 , respectively, and is onethird larger compared to network\#2 with a degree centrality of 0.39 .

A visual representation of the analyzed networks can be found in Figure 2.

All relationships were considered as unidirectional and therefore represented as directed graphs. The node size depends on the betweenness-centrality, meaning that the larger the nodes, the shorter their geodesic paths of connections to all other nodes and the more central the respective actor. In network\#2 and network\#3, one institution each from the subject area health has the greatest betweenness-centrality whereas the most central actors within network\#1 are a social and educational institution together with an actor in the field of nutrition.

\section{Frequency of contact}

As the largest network to be studied, network\#1 had the highest average degree (9.2) with its 151 out of 400 possible contact opportunities. Putting non-contacts in the background, the most frequent form of contact in all three networks is quarterly, with quarterly contact in network\#3 accounting for two-thirds of the total contact within the network. Remarkable at network\#2 is the strong annual and daily contact between the institutions compared to the other two networks (see Figure 3 ).

A visual representation of the analyzed networks regarding the frequency of contact can be found in Figure 4.

\section{Intensity of collaboration}

The most frequent intensity of collaboration in all three networks was informal collaboration to achieve common goals, which in the case of network\#3 even accounted for more than half of the collaboration types. Considering the four types of existing collaboration, network\#1 stands out with more than one fifth of the strongest collaboration as a formal team (joint planning/sharing of staff and resources), although the network size should not be underestimated (see Figure 5).

A visual representation of the analyzed networks regarding the intensity of collaboration can be found in Figure 6. 


\section{Discussion}

In this paper, network analytical methods were used to give an overview of the three model regions involved in the project 'Familie'.' Their structural and process characteristics as well as the interconnectedness of the actors within each network were outlined. The networks were mainly characterized by their different sizes as well as different distribution of network partners in terms of their subject matter and structure. Network partners who are in contact interact with each other mostly on a quarterly basis and in the context of informal collaboration. Social networks are particularly important in terms of supporting partnerships and collaborations within a research process (35).

If the three networks are placed in the context of their structure for community health promotion, the following characteristics can be identified. Although network\#2 for community health promotion is still in its early stages, it is intriguing to note that it has both the highest network density but also the lowest degree centrality. In contrast, network\#3, with its already very developed structure for community health promotion, has the lowest network density and, similar to network\#2, one-third greater degree centrality than network\#3. High degree centrality can have both benefits and drawbacks, as a small number of stakeholders connect many other institutions that would otherwise not be connected. This can have a positive impact on the effective dissemination of information and strengthen networking with other institutions through these key stakeholders, but at the same time, communication depends on these gatekeepers and could represent bottlenecks with regard to the transfer of information (36). In network\#2 and network\#3, one institution each from the subject area health has the greatest betweenness-centrality and represents an important communication interface. Betweenness centrality is an indicator of an actor's influence in a network and provides information about the extent of its control potential. Actors with high betweenness centrality serve as a strong link between other network partners through their strategic network placement and serve, for example, as mediators of information $(26,31)$. In network\#1, on the other hand, the most central actors are a social and educational institution and an actor in the field of nutrition. In this region, however, there is a greater number of stakeholders dealing with the subject area health on a superordinate level compared to the other two regions, which in turn could explain the lower centrality of these institutions. When analyzing networks as a whole, adjusting for network size is important because the larger the network, the less dense it becomes and the higher the degree of centralization (17). Especially with regard to the high degree centrality in \#network1 and \#network3, the very short average path length in all three networks represents an optimal condition for the implementation of community health promotion projects, as most relevant institutions seem to be quickly accessible, which facilitates information exchange and communication.

Network analysis served as a suitable tool for making existing network structures visible in the 'Familie ${ }^{+\prime}$ project in the three model regions involved. Although the networks are still in their initial stages and do not yet have any influence on the project, it is important to survey and analyze the already existing structures. The socio-ecological approach, which includes a multi-setting as well as participatory design and underpins the community-based obesity prevention project 'Familie ${ }^{+\prime}$, is broad, therefore the present study focused on the analysis of stakeholders from different network levels and their interaction. 
Interactions were captured similarly to already existing studies measured by type and extent of contact, but further research is needed to examine community networks in a more interpretative analysis that surveys barriers and contributions to communication, rules of communication as well as dimensions and quality of interaction $(27,35)$. Nevertheless, a foundation could be created at the beginning of the project simply by pointing out previously known and unknown actors and fields of work, on which the respective municipalities can build and expand their networks. A specific exchange between the stakeholders can initiate an intensive engagement with the topic of health promotion of primary school children, common goals, development opportunities and ideas in further project phases. A project guide on the topic of strategic design of municipal prevention and health promotion indicates that network analyses as part of the assessment of the current situation in the early phase of municipal health promotion projects lead into the sustainable processing of the respective topics and needs for action (37).

Based on the results of the network analysis and the observation that the urban model region with its very distinctive structure for community health promotion already has a well-connected network and a health facilitator, it would be desirable to initiate further expansion and strengthening of the network at the health policy level in the other model regions by providing necessary ressources. To achieve systematic networking of the health-related network levels, additional health facilitators can be deployed whose main task is to link the primary and tertiary levels. This approach has already been successfully implemented in a Brazilian family health program (14) and could also be used within 'Familie' ${ }^{+\prime}$ to strengthen networking and information exchange between the health policy level and primary schools including children and their families. In addition, sufficient resources must be made available to strengthen the network so that other network and cooperation partners can be involved in a participatory manner. For further planning and a successful course of the 'Familie ${ }^{+\prime}$ project, it would be valuable to identify potential organizational collaborations in order to maintain and strengthen partnerships and to identify any gaps in the network. To date, there is no evidence that the use of a network analysis provides intelligent targeting of key relationships and collaborations (38). A comparison of the networks of the three model regions over the course of the intervention would be useful to identify different multipliers that could be beneficial for knowledge transfer to the target groups.

\section{Limitations}

This study also has some potential limitations in the context of preparing and conducting the network analysis. The network definition was based on the subjective results of the individual expert interviews within the respective municipalities, therefore there may be institutions that were forgotten or otherwise excluded. The institutional contacts selected to conduct the network analysis were those that appeared to have the best knowledge of the day-to-day operations of their institutions. Still, the information provided by some respondents could be limited and inconsistent due to institutional changes (including the Corona pandemic), job changes, and changes in roles and responsibilities. Another problem in conducting the survey-based network analysis was the non-participation of potentially relevant network partners in all three municipalities due to inaccessibility by email or phone and lack of time on the part of 
stakeholders. The study is a subjective survey, implying that the results are under the influence of social desirability. At the municipal level, it should again be noted that the networks have different prerequisites due to their location (urban versus rural) as well as different levels of prior experience in municipal health promotion. The hierarchical position as well as the objectives of the experts and individual stakeholders are decisive for the contribution of resources that have a beneficial effect on the project 'Familie ${ }^{+1}$ as well as on community health promotion in the model regions. Nevertheless, the study had a strength with its sufficiently high response rate, as the incomplete data sets appeared to be representative of those involved in the overall project. The inclusion of adjusted control variables as well as the identification of communication-related confounders would be advisable, as the interpretation of the results is influenced by different network sizes as well as structural characteristics or unusual events.

\section{Conclusions}

This paper outlines the application of network analysis in the context of the project 'Familie ${ }^{+\prime}$, a community-based intervention for the prevention of obesity among primary school children in Germany. By mapping structural and process characteristics in three model regions, initial community network structures, existing relationships and collaborations among stakeholders relevant to the project were able to be identified. The network models showed some similar as well as diverse characteristics, mainly due to their different sizes and already existing structures in the field of municipal health promotion. Based on the results of the network analysis, it appears to be useful to initialize a community health facilitator provided with necessary resources and training at the health policy level in community health promotion projects, irrespective of the rural or urban structure of the region. Participatory engagement of relevant actors initiated by the facilitator can have a positive influence on the effective dissemination of information and networking with other stakeholders across the network levels. This could allow further deciphering of the impact of network structure on community-based obesity prevention interventions.

\section{Abbreviations}

'Familie ${ }^{+}$

'Familie ${ }^{+}$:Gesundes zusammenleben in Familie und Schule'

'Family ${ }^{+}$

'Family+:Living healthily together in family and school'

\section{Declarations}

\section{Ethics approval and consent to participate}

The study was submitted to and approved by the Ethics Committee of the University of Konstanz (01.10.2021 / Identificationcode: 41/2021). Written informed consent was obtained from all participants.

\section{Consent for publication}


Not applicable.

\section{Availability of data and material}

The datasets used and/or analysed during the current study are available from the corresponding author on reasonable request

\section{Competing interests}

The authors declare that they have no competing interests.

\section{Funding}

This collaborative project funded by the German Federal Ministry of Health (BMG).

\section{Authors' contributions}

KB: data preparation, data collection, data analysis, interpretation and drafting the manuscript. SP: data preparation, data collection. AZ: conception of research, conception of interviews and questionnaires. AZ and $\mathrm{HW}$ : defining research question and idea of the design of the analysis plan, drafting and reviewing the manuscript, supervising the direction of the study, quality assessment. All authors read and approved the manuscript.

\section{Acknowledgements}

The data used here originate from a collaborative research project ('Familie ${ }^{+}$- Gesundes Zusammenleben in Familie und Schule' / 'Family ${ }^{+}$- Living healthily together in family and school') within the following institutions and persons are involved: University of Konstanz, Department of Sports Science, Social and Health Sciences (Prof. Dr. Martina Kanning, Dr. Christina Niermann, Felix Arway), Technical University of Munich, Department of Sport and Health Sciences (Prof. Dr. Filip Mess, Friederike Butscher), platform nutrition and physical activity (peb e.V.) (Mirko Eichner, Anja Kretzer), Leipzig University, Faculty of Sports Science, Institute of Exercise and Public Health (Prof. Dr. Petra Wagner). We would like to thank all the above-mentioned institutions and persons for their cooperation and contribution to this collaborative research project.

\section{References}

1. Ulijaszek S. With the benefit of Foresight: Obesity, complexity and joined-up government. BioSocieties. 2015;10(2):213-28.

2. Jancey J, Leavy JE, Pollard C, Riley T, Szybiak M, Milligan M, et al. Exploring network structure and the role of key stakeholders to understand the obesity prevention system in an Australian metropolitan health service: study protocol. BMJ Open. 2019;9(5). 
3. Schienkiewitz A, Damerow S, Schaffrath Rosario A, Kurth BM. [Body mass index among children and adolescents: prevalences and distribution considering underweight and extreme obesity : Results of KiGGS Wave 2 and trends]. Bundesgesundheitsblatt Gesundheitsforschung Gesundheitsschutz. 2019;62(10):1225-34.

4. World Health Organization. Noncommunicable diseases: Childhood overweight and obesity: World Health Organization; 2020 [Available from: https://www.who.int/news-room/q-adetail/noncommunicable-diseases-childhood-overweight-and-obesity.

5. Spinelli A, Buoncristiano M, Kovacs VA, Yngve A, Spiroski I, Obreja G, et al. Prevalence of Severe Obesity among Primary School Children in 21 European Countries. Obesity Facts. 2019;12(2):244-58.

6. McGlashan J, Nichols M, Korn A, Millar L, Marks J, Sanigorski A, et al. Social network analysis of stakeholder networks from two community-based obesity prevention interventions. PLoS One. 2018;13(4).

7. Mikhareva V, Taranova E. Übergewicht bei Kindern und Jugendlichen in Deutschland. 2019.

8. Waters E, de Silva-Sanigorski A, Hall BJ, Brown T, Campbell KJ, Gao Y, et al. Interventions for preventing obesity in children. Cochrane Database Syst Rev. 2011(12).

9. Salway S, Green J. Towards a critical complex systems approach to public health. Critical Public Health. 2017;27(5):523-4.

10. Wolfenden L, Wyse R, Nichols M, Allender S, Millar L, McElduff P. A systematic review and metaanalysis of whole of community interventions to prevent excessive population weight gain. Preventive Medicine. 2014;62:193-200.

11. Brown T, Moore THM, Hooper L, Gao Y, Zayegh A, ljaz S, et al. Interventions for preventing obesity in children. Cochrane Database of Systematic Reviews. 2019(7).

12. The Centre for Allied Health Evidence. Community-based Interventions: A Rapid Review. A technical report prepared for Department of Health, Victoria. 2009.

13. Dahlgren G, Whitehead M. Policies and strategies to promote social equity in health. Background document to WHO - Strategy paper for Europe. Institute for Futures Studies, Arbetsrapport. 1991;14.

14. Bruns W. Gesundheitsförderung durch soziale Netzwerke: Möglichkeiten und Restriktionen. Wiesbaden: Springer VS; 2013.

15. Bronfenbrenner U. The ecology of human development: Experiments by nature and design: Harvard university press; 1979.

16. Metz T. Netzwerkanalyse. In: Jäckle S, editor. Neue Trends in den Sozialwissenschaften: Innovative Techniken für qualitative und quantitative Forschung. Wiesbaden: Springer Fachmedien Wiesbaden; 2017. p. 203-37.

17. Valente TW. Social networks and health: models, methods, and applications. Oxford u.a.: Oxford University Press; 2010.

18. Jancey J, Vidler A-C, Leavy JE, Chamberlain D, Riley T, Pollard CM, et al. Understanding Prevention Networks in a Local Government Area: Insights From a Social Network Analysis Among Western 
Australian Nutrition, Physical Activity, and Obesity Prevention Programs. Health Promotion Practice. 2021;0(0).

19. Karacabeyli D, Allender S, Pinkney S, Amed S. Evaluation of complex community-based childhood obesity prevention interventions. Obesity Reviews. 2018;19(8):1080-92.

20. McGlashan J, Johnstone M, Creighton D, de la Haye K, Allender S. Quantifying a Systems Map: Network Analysis of a Childhood Obesity Causal Loop Diagram. PLoS One. 2016;11(10).

21. McGlashan J, de la Haye K, Wang P, Allender S. Collaboration in Complex Systems: Multilevel Network Analysis for Community-Based Obesity Prevention Interventions. Sci Rep. 2019;9(1).

22. Blackford K, Leavy JE, Vidler AC, Chamberlain D, Pollard C, Riley T, et al. Initiatives and partnerships in an Australian metropolitan obesity prevention system: a social network analysis. BMC Public Health. 2021;21(1).

23. Mieg HA, Näf M. Experteninterviews. 2. Auflage ed. Auflage, editor. Institut für MenschUmweltSysteme (HES): ETH Zürich; 2005.

24. Dresing T, Pehl T. Praxisbuch Interview, Transkription \& Analyse. Anleitungen und Regelsysteme für qualitativ Forschende. 6. Auflage ed. Marburg 2015.

25. Mayring P. Qualitative Inhaltsanalyse. In: Mey G, Mruck K, editors. Handbuch Qualitative Forschung in der Psychologie. Wiesbaden: VS Verlag für Sozialwissenschaften; 2010. p. 601-13.

26. Schnegg M, Lang H. Die Netzwerkanalyse: Eine praxisorientierte Einführung. Methoden der Ethnographie. 2002;1:1-55.

27. Schoen MW, Moreland-Russell S, Prewitt K, Carothers BJ. Social network analysis of public health programs to measure partnership. Social Science \& Medicine. 2014;123:90-5.

28. Luke DA, Harris JK. Network Analysis in Public Health: History, Methods, and Applications. Annual Review of Public Health. 2007;28(1):69-93.

29. Harris JK, Luke DA, Burke RC, Mueller NB. Seeing the forest and the trees: Using network analysis to develop an organizational blueprint of state tobacco control systems. Social Science \& Medicine. 2008;67(11):1669-78.

30. Uddin S, Mahmood H, Senarath U, Zahiruddin Q, Karn S, Rasheed S, et al. Analysis of stakeholders networks of infant and young child nutrition programmes in Sri Lanka, India, Nepal, Bangladesh and Pakistan. BMC Public Health. 2017;17(2):405.

31. Wäsche H, Dickson G, Woll A, Brandes U. Social network analysis in sport research: an emerging paradigm. European Journal for Sport and Society. 2017;14(2):138-65.

32. Honeycutt TC, Strong DA. Using Social Network Analysis to Predict Early Collaboration Within Health Advocacy Coalitions. American Journal of Evaluation. 2012;33(2):221-39.

33. Valente T, Chou C, Pentz M. Community Coalitions as a System: Effects of Network Change on Adoption of Evidence-Based Substance Abuse Prevention. American journal of public health. 2007;97:880-6. 
34. Borgatti SP, Everett MG, Freeman LC. Ucinet for Windows: Software for social network analysis. Harvard, MA: analytic technologies. 2002;6.

35. Bright CF, Haynes EE, Patterson D, Pisu M. The Value of Social Network Analysis for Evaluating Academic-Community Partnerships and Collaborations for Social Determinants of Health Research. Ethnicity \& Disease. 2017;27(Suppl 1):337-46.

36. McCullough JM, Eisen-Cohen E, Salas SB. Partnership capacity for community health improvement plan implementation: findings from a social network analysis. BMC Public Health. 2016;16:566.

37. Erven S, Gliszczynski M, Gottschall S, Oesterle L. Kontextcheck: Kommunale Prävention und Gesundheitsförderung strategisch gestalten. 2 ed. Hannover: Altgeld, Thomas; 2020.

38. Chambers D, Wilson P, Thompson C, Harden M. Social network analysis in healthcare settings: a systematic scoping review. PLoS One. 2012;7(8).

\section{Figures}




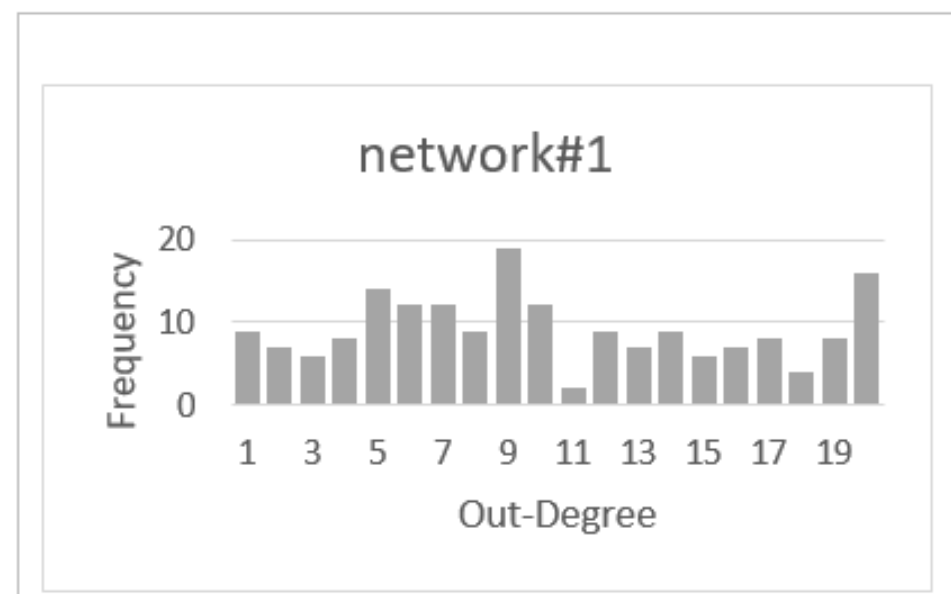

(a)

network\#2

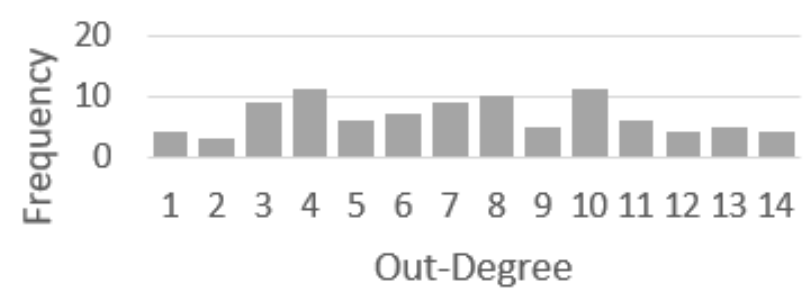

(b)

network\#3

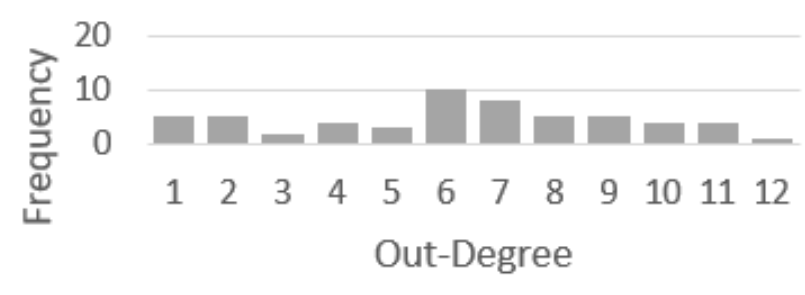

(c) network\#1

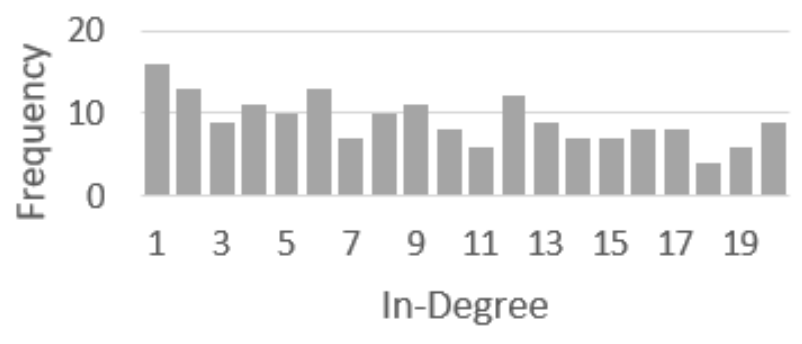

(d)

network\#2

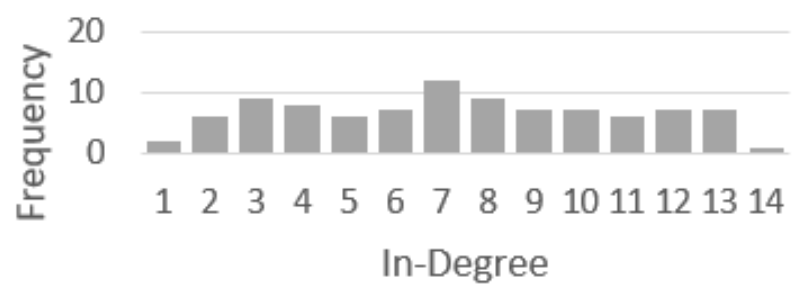

(e)

network\#3

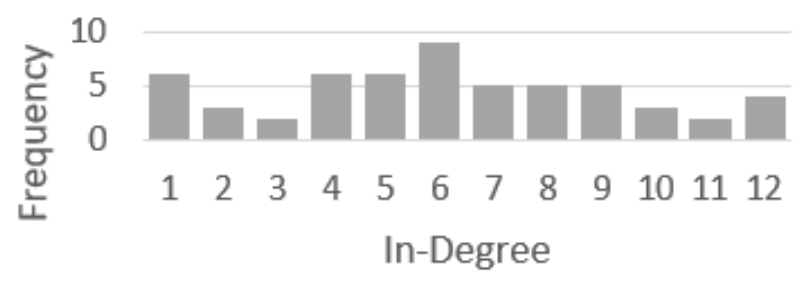

(f)

\section{Figure 1}

Degree distributions of all networks 


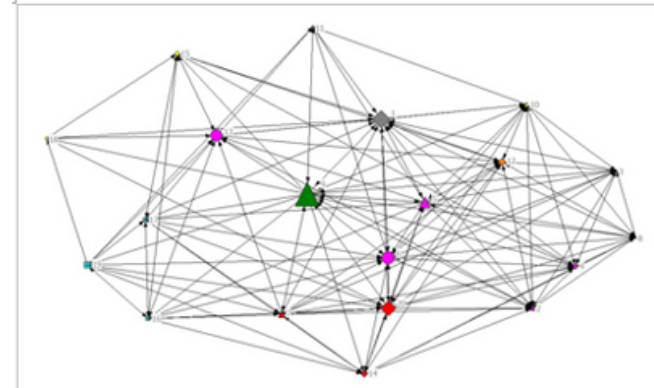

(a) network\#1

size $=20$, density $48 \%$

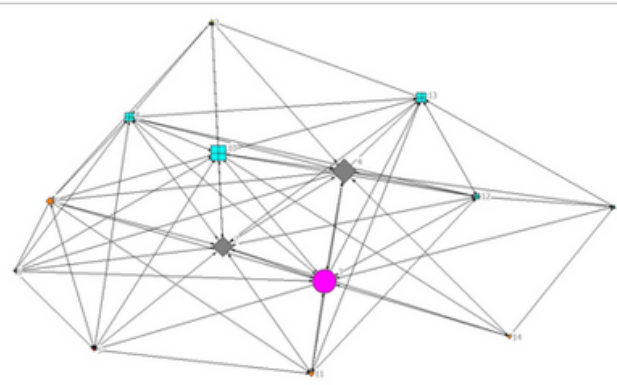

(b) network\#2

size $=14$, density $52 \%$

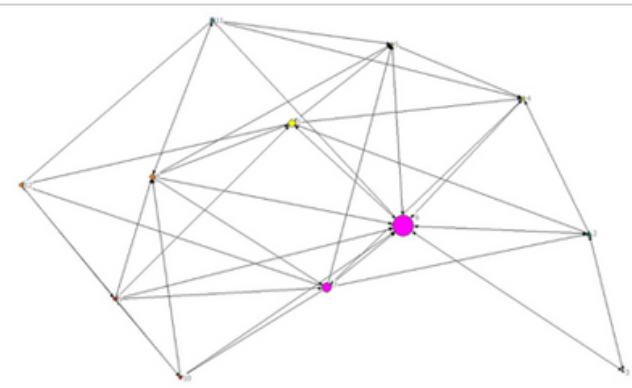

(c) network\#3

size $=12$, density $42 \%$

\section{Figure 2}

Vizualization of network data for all networks. Node size by betweeness. Colours by subject area: pink = health, green = nutrition, yellow $=$ sports $/$ exercise, orange $=$ leisure, red $=$ family, turquoise $=$ elementary schools, grey = social and educational institutions. Symbols by structural level: circle = office level, up triangle $=$ network level, square $=$ association level, box = elementary schools

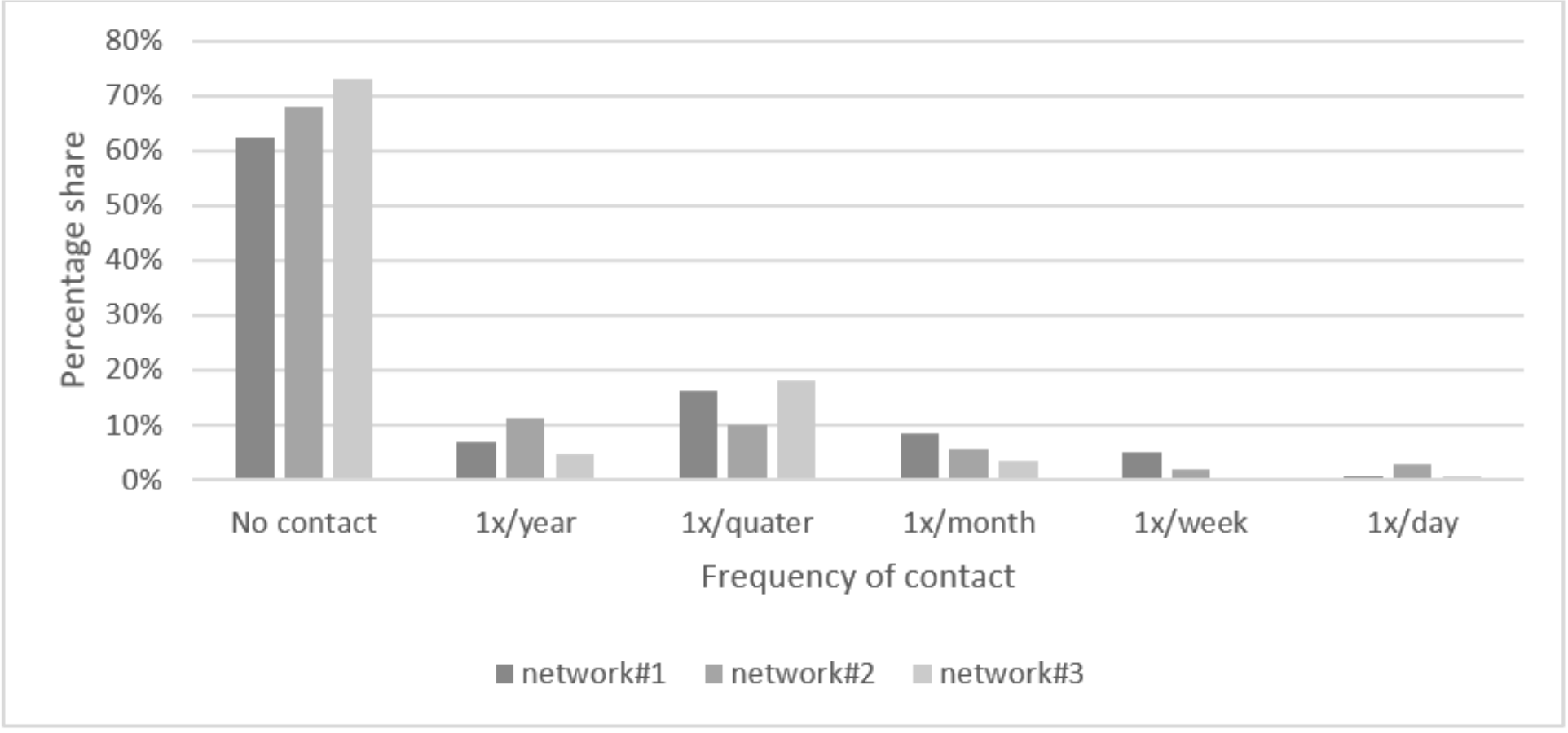

\section{Figure 3}

Distribution of contact frequency for all networks 


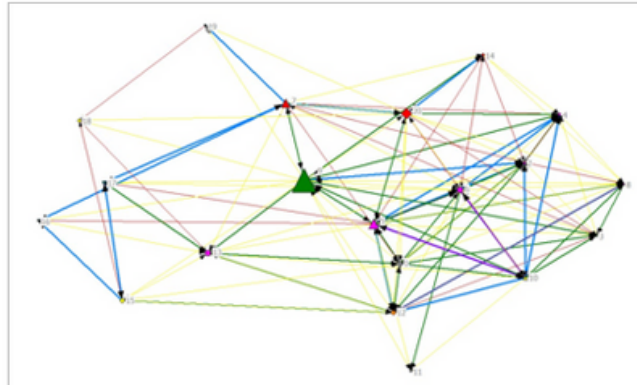

(a) network\#1

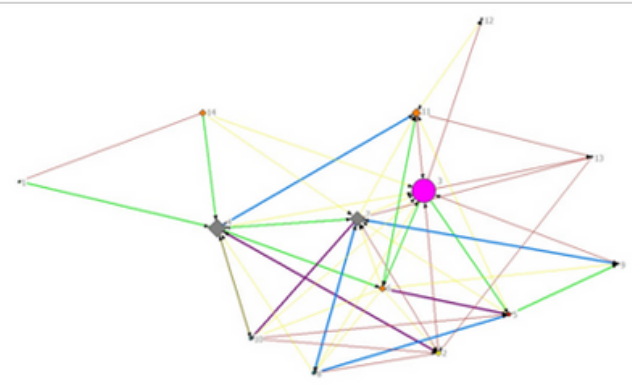

(b) network\#2

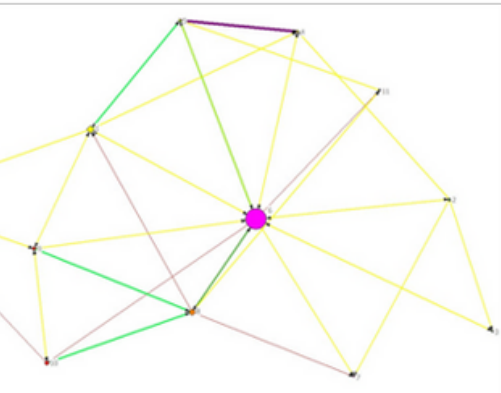

(c) network\#3

\section{Figure 4}

Vizualization of network data regarding frequency of contact for all networks. Node size by betweeness.

Frequency of contact: no colour $=$ no contact, red $=1 \mathrm{x} /$ year, yellow $=1 \mathrm{x} /$ quarter, green $=1 \mathrm{x} / \mathrm{month}$, blue $=$ $1 \mathrm{x} /$ week, purple $=1 \mathrm{x} /$ day .

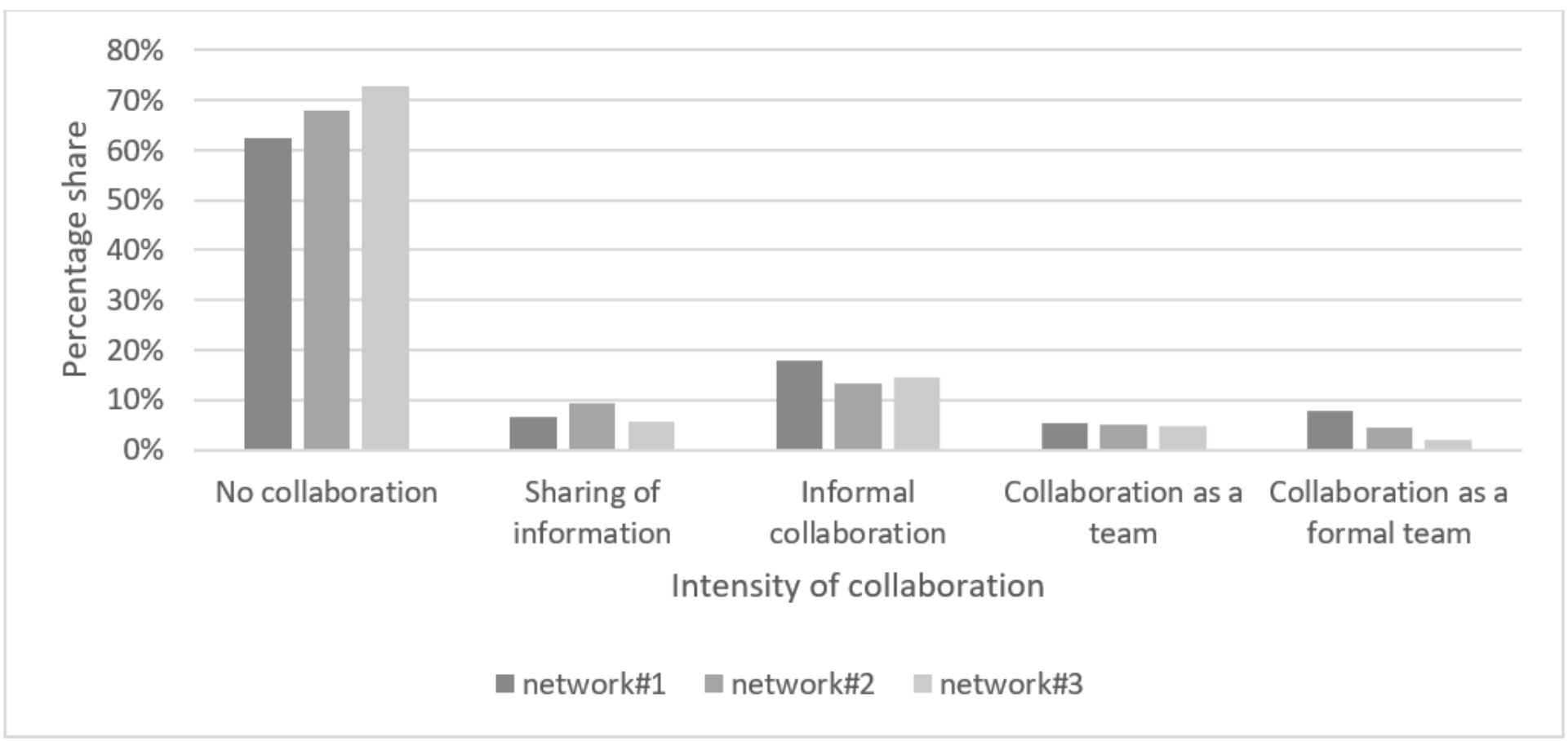

\section{Figure 5}

Distribution of collaboration intensity for all networks 


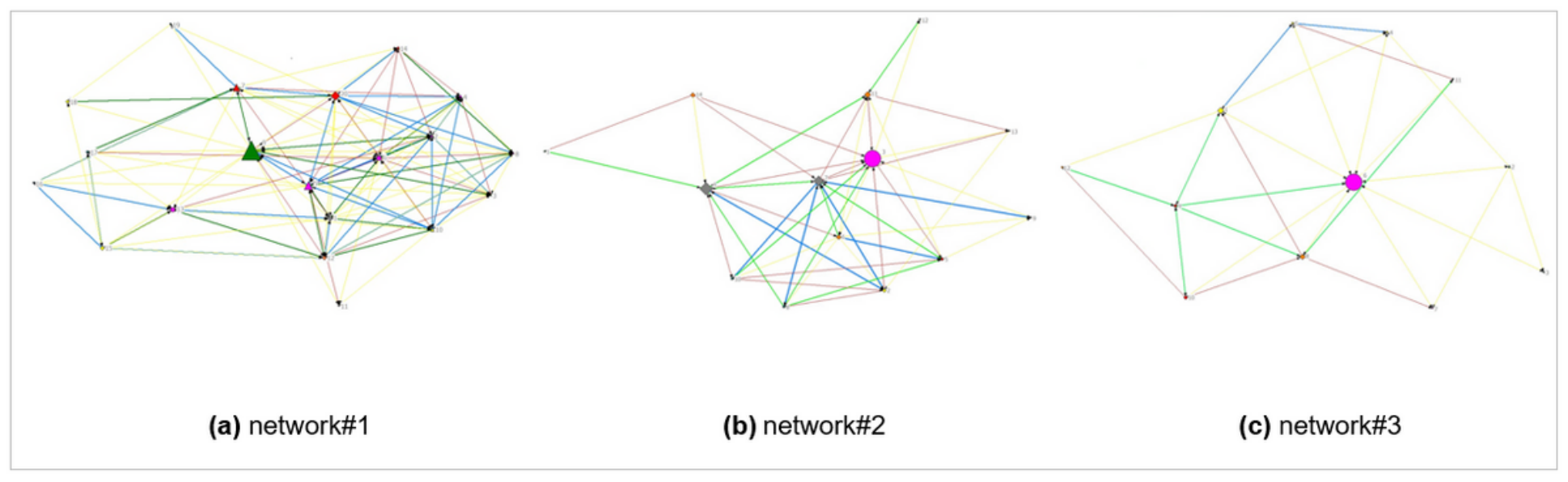

\section{Figure 6}

Vizualization of network data regarding intensity of collaboration for all networks. Node size by betweeness. Intensity of collaboration: no colour = no collaboration, red = sharing of information, yellow = informal collaboration to achieve common goals, green = collaboration as a team with specific responsibilities, blue $=$ collaboration as a formal team (joint planning/sharing of staff/ressources

\section{Supplementary Files}

This is a list of supplementary files associated with this preprint. Click to download.

- Questionnaireenglish160122.pdf 